\title{
Estimate the Forest Recreational Values of Zhangjiajie in China Using a Contingent Valuation Method
}

\author{
Zhiming Leng, Yihui Lei \\ Business School, Jishou University, Hunan, China. \\ Email:1zm9306@126.com \\ Received March $3^{\text {rd }}, 2011$; revised March 30 ${ }^{\text {th }}, 2011$; accepted April 21 $1^{\text {st }}, 2011$.
}

\begin{abstract}
Zhangjiajie, a World Natural Heritage, is located in Chinese Wuling hinterland and rich in forest resources with coverage rate 64.61 percent of forest. Zhangjiajie was listed in World Natural Heritage Catalogue by the UNESCO in 1992 and is one of the most important tourism sites in China. As a leading and pillar industry, the tourism achieved remarkable effects on the economic development, where forest eco-tourism has played an important role. The purpose of this research is to estimate the forest recreational values of Zhangjiajie using a contingent valuation method (CVM). The empirical results show that non-use values account for the majority of the total values of Zhangjiajie. On this basis, the contingency table and Chi square test method are employed to test the related factors influencing tourists' willingness to pay (WTP). The test results show that educational level and income level are the most important factors influencing WTP.
\end{abstract}

Keywords: Forest Recreation, Recreational Values, Contingent Valuation Method, Zhangjiajie

\section{Introduction}

Zhangiiajie, covering 1012 acres forest land, or 71 percent of the Zhangjiajie territory, is well-known as its forest resources. In 2009 the number of tourists has been over 20 million people and the tourism industry has been the pillar of the economy of Zhangiajie. Therefore it is very significant to estimate the forest recreational values.

Currently, to estimate the forest recreational values mostly used travel cost method (TCM) and contingent valuation method (CVM). From the view of consumer surplus, Marshall consumer surplus is calculated in TCM, while the Hicks consumer surplus is calculated in CVM, so the two methods have very different theoretical basis. The TCM mainly employs the expenditures of tourist to establish the demand curve for recreational services and solve the consumer surplus to calculate the use values of recreational values. With the utility maximization principle and hypothetical market conditions, the CVM directly investigates the WTP for improving environmental benefits and the WTA for environmental losses to derive their economic values. Most of the literatures about forest recreational value estimating use the CVM, especially for estimating the choice values, preserve values and the other non-use values the CVM is the best choice. Known as the most promising valuation method for environmental benefits, the CVM not only can be used to estimate the use values, but also the non-use values of tourism sites by directly investigating consumers. Therefore, this study used CVM to estimate the values of Zhangjiajie forest recreation.

In fact, the CVM has been commonly employed as one of the standard approaches to measure the forest recreational values. In 1963 Davis firstly proposed and applied CVM to estimate the recreational values of forest camping and hunting. Since then the CVM increasingly was introduced to estimate the economic value natural resources, hunting and aesthetic benefits [1,2]. Reference [3] concluded that the use of CVM in developing countries may derivate a lower public willingness to pay. On this basis, reference [4] pointed out that the CVM was the most widely applicable method, which can be used to estimate the use values of resources and so far was the only approach to learn about all the use and non-use values of environmental goods. The CVM was used to value the Chinese urban residents' WTP for improving river water quality [5]. Reference [6] used CVM to re- 
search the Sweden residents' WTP for improving the quality of atmospheric environment. Reference [7] used TCM to estimate the recreational values of forest resources and public parks. The effectiveness of CVM and calculation model was studied $[8,9]$. In the process of the development of CVM, the research scope has been expanded from the recreational value of environmental goods or services to the effectiveness of environmental improvement and the economic losses of environmental damage [10,11]. In China, reference [12] did a comprehensive research on the non-use values of biodiversity of Changbai Mountain Nature Reserve. Reference [13] employed the CVM to estimate the service values of the landscape of Suzhou River in Shanghai. The CVM was also used to estimate the values of ecosystem services $[14,15]$. The CVM derives the values of environmental goods by inquiring the WTP for improving environmental quality or the willingness to accept (WTC) for tolerating environmental damage [16]. Compared with travel cost method, the CVM can directly investigate the WTP of consumers, so it is the most important and widely used method for estimating the environmental benefits [17]. All the previous mentioned references show that the research scope of recreational values continue to be broadened and its assessment methods and the processes have already developed to a systematical direction. But in China, there is a certain gap with foreign in both theory and practice of recreational values estimation. This paper statistically analyzed the WTP of tourists to construct a regression model of survival function, then employed the VCM to calculate the use, heritage/selectionion and preserve values of Zhangjiajie forest recreation. On this basis, the contingency table analysis and Chi square test method were employed to test the related factors for tourists' WTP, then the effects of gender, age, educational level and income level on the WTP were analyzed.

The rest of this paper is organized as follow. Section II describes the study area and the evaluation methodology. Section III presents a brief description of how to collect and process data. Section IV estimates and analyzes the forest recreational values, including use, heritage or selection and preserve values. Conclusions and discussions are presented by section $\mathrm{V}$.

\section{Methodology}

\subsection{Study Area}

Zhangjiajie city, with a total area of 9516 square kilometers and a total population of 1.6 million, almost 77 percent belong to ethnic minority groups, is located in the northwest of Hunan Province. In 1982, Zhangjiajie was named China's first national forest park and was listed into the World Natural Heritage Catalogue by the UNESCO in 1992. What's more, Zhangjiajie was awarded the title of "World Geological Park" in 2004. Zhangjiajie, covering 1012 acres forest land, or 71 percent of the Zhangjiajie territory, is rich in forest resources. There are over 300 marvelous scenic spots in Zhangjiajie, such as Tianzi Mountain, Yangjiajie and Baofeng Lake. As the core of Zhangjiajie attractions, Wulingyuan Scenic and Historic Interest Area is composed of Zhangjiajie National Forest Park, two major Nature Reserves-Tianzi Mountain and Suoxi Valley and the new Yangjiajie Scenic Area, stretching over a total area of 397 square kilometers.

The entire area is covered with towering cliffs of sandstone of quartz and dense unspoiled forests that conceal fantastic caves full of stalactites and stalagmites. The quartzite sandstone hills in Wulingyuan are unique in their large number and fairly pure composition (being $75 \%-95 \%$ of quartz). With the changes of seasons and the weather, they constantly present different views to spectators. The highest peak in this area is Tuerwangyue Feng or Rabbit Watching the Moon Peak and Mt. Tianzi is particularly recommended for its good view. Near the downtown area of Zhangjiajie stands grand Tianmen Mountain called "the Soul of Wuling", and there is a beautiful Maoyan River that enjoys the reputation of "one-hundred-li long gallery", a Jiutian Cave named "the number-one cave in Asia" and other charming scenic spots in Wulingyuan. All these natural wonders are worth exploring. After more than twenty years of development, tourism industry has become the leading industry in Zhangjiajie, which has stimulated the development of other industries related to tourism. In the meantime, ecotourism has been developed greatly here. Today Zhangjiajie has become the world-famous eco-tourist destination.

\subsection{Survey Process}

The survey process of CVM is described as follows.

1) Design a program. For the subjects of the investigation, a questionnaire must be designed and whether WTP or WTA is employed. Theoretically, the values of these two measurement methods should be the same or similar, but practical value of WTA usually are greater than the one of WTP. As a more objective measurement method, WTP is chose in this paper.

2) Choose the approach guiding WTP. The guiding approaches of WTP are divided into continuous and discrete contingent valuation. Continuous contingent valuation consists of repeated bidding game, open-ended question format and payment card format, while discrete contingent valuation primarily consists of dichotomous choice format. This paper used a questionnaire survey of 
payment card format, which allows respondents to choose a maximum payment number or range.

3) Sampling survey. The survey was executed through interviews, telephone and E-mail. Before the formal survey a pre-survey has been done for improving the questionnaire.

4) Analyze the survey results. Use appropriate mathematical methods for statistical analysis to draw the conclusions.

\subsection{Evaluation Model}

According to the needs of this study and the characteristics of questionnaire, this paper chose payment card format and non-parameter model to calculate mean WTP. Assume WTP is consistent with a probability distribution, then there is a cumulative density function $F(x)$ and the corresponding survival function $S(z)=1-F(x)$. The mean WTP can be expressed as follows:

$$
\mathrm{WTP}=\int_{0}^{a}(1-F(z) d z)=\int_{0}^{a} S(z) \mathrm{d} z
$$

The median WTP is the one of 50 percent of cumulative probability, which can be expressed as the following equation:

$$
\mathrm{WTP}=F^{-1}(0.5)=S^{-1}(0.5)
$$

To multiple the median or mean WTP by the total number of tourists can get the forest recreational values.

\section{Data Sources and Processing}

\subsection{Data Sources}

In October 2009, research team has investigated in Zhangjiajie National Forest Park, Tianzishan natural beauty and Suoxiyu natural scenic spot. In this investigation, in order to facilitate the investigation and statistics, the research team only interviewed the tourists from China and calculated the forest recreational values according to the total number of Chinese tourists in 2009. From the composition of tourism revenue we can see that tourism foreign exchange earnings accounted for only 1.47 percent. From tourists source structure we can see that foreign tourists accounted for only 4.37 percent. Therefore ignoring the WTP of foreign tourists has little effect on the estimation of Zhangjiajie forest recreational values. In the process of investigation, firstly investigators described an overview of scenic spots in Zhangjiajie, a hypothetical exchange market and a payment approach, and then asked the WTP of respondents. In the whole investigation process, the respondents' willingness and the efficiency of questionnaire were high. Since the release of questionnaire used a random sampling approach and the respondents covered the whole tourism areas, the survey achieved the extensive goal required by CVM [20]. The research team released 198 questionnaires, of which 185 questionnaires were valid. The questionnaire includes two parts.

1) Basic situations of tourists consist of gender, age, occupation, educational level, income level, travel costs and visit frequency. Age and income level use an open questions and answers, while occupation and educational level use a closed questions and answers.

2) The WTP for the use, heritage/selection and preserve values. In the respect of use values, to ensure that the willingness of answers is for paying the forest scenes, we emphasize the natural landscape and strip out the cultural landscape. For example, a question is "In order to enjoy the natural scenery, you are willing to pay the maximum money for the travel". In the respect of heritage/selection values, we emphasize whether for themselves or future generations can continue to enjoy the natural forest landscape. For example, a question is "For you and your future generations can enjoy the scenery, how much you are willing to pay each year". In the respect of preserve value, a question is "In order to protect the living environment of wild animals and plants, how much you are willing to pay each year". The choice of WTP employs interval data, which consist of RMB 0, RMB 1 - 50, RMB 51 - 100, RMB 101 - 150, RMB 151 200, RMB 201 - 300, RMB 301 - 400, RMB 400 above.

\subsection{Data Processing}

According to the characteristics of questionnaire, the effects of gender, age, occupation, educational level, income level, tourism cost and visit frequency on WTP have been analyzed. The gender, age, occupation and educational level are regarded as dummy variables. Use the random samples to get the WTP of tourists for the forest recreational functions and the corresponding mean and median WTP.

\section{Empirical Study}

\subsection{Descriptive Statistics of Basic Information of Tourists}

The descriptive statistical results of 185 valid questionnaires are described as follows:

1) Gender information. There are 106 males and 79 females, and males account for 57.30 percent of the total number of tourists.

2) Age information. Overall, 21 - 30 years old tourists account for 26.49 percent, 31 - 40 years old tourists account for 31.35 percent, and 41 - 50 years old tourists account for $18.92 \%$ percent.

3) Occupation. There are 34 administrative officers and managers, 48 junior officers, 75 teachers and students, 11 research staffs, and 17 peoples of other occupations. 
Tourists mainly consist of administrative officers and managers, as well as teachers and students.

4) Educational level. There are 12 peoples with graduate degree or above, 69 with university education, 26 with high school diploma, 40 with junior high school education and 38 with primary education or below.

5) Income levels. The tourists with RMB $1001-2000$ per month account for 40 percent of the total visitors, those with RMB 2001 - 3000 per month account for 22.70 percent, and those with below RMB 1000 per month account for 20.54 percent.

6) Tourism cost. The tourists spending RMB $501-1000$ account for 42.70 percent of the total visitors, those spending RMB 500 or below account for 34.59 percent, and those spending RMB 1001-1500 account for 11.35 percent.

7) Visit frequency. There are 127 tourists for the first visit and 58 tourists are often visiting. Among them, the tourists for the first visit are 68.65 percent of the total visitors.

\subsection{Calculate the Recreational Values}

\subsubsection{Calculate the Use Values}

Table 1 presents the frequency of use values of forest recreation. To change the percentage of the survival function into a decimal and take the upper limit of each WTP to calculate the values of the survival function can get the Table 2 and Figure 1.

According to Figure 1, in the interval $[0,400]$ the quadratic, cubic curve and exponential curve more fit the observations than linear, so linear function can be excluded. The regression results of the four functional forms are presented in Table 3.

As can be seen from Table 3, the quadratic, cubic and exponential forms are tested by the $F$-value, which indicate that the three models are effective. However, analysis of variance shows the $P$-value of quadratic coefficient of cubic form is 0.451 , which is greater than 0.05 . Therefore the cubic form does not apply to this study. The $P$-value of coefficient of quadratic and exponential forms are 0.000 and 0.002 respectively, which are lower than 0.05 . Therefore, to choose the quadratic form is appropriate in the interval $[0,400]$, while the interval is greater than 400 , the exponential form is more appropriate. The sub-function of regression model is described as follows:

$$
S(z)=\left\{\begin{array}{l}
1.0024-0.0040 z+0.0000053 z^{2}(0 \leq z \leq 400) \\
1.0892 \exp (-0.0060 z)(z>400)
\end{array}\right.
$$

when $S(z)$ equates 0.5 , the median WTP equates 159.17 . Then the mean WTP is:

$$
\begin{aligned}
\mathrm{WTP} & =\int_{0}^{400} S(z) \mathrm{d} z+\int_{400}^{\alpha} S(z) \mathrm{d} z \\
& =194.04+16.48=210.52
\end{aligned}
$$

In $2009,18,477,400$ domestic people and 806,800 overseas people were reported to have visited Zhangjiajie. Because the survey interviewed only domestic tourists, in accordance with $18,477,400$ people in 2009 the use values of Zhangjiajie forest recreation are RMB 29.41 38.90 billion.

In all variables, gender and visit frequency are the twocategorical variables, while age, occupation, educational level, income level, travel costs are multi-categorical variables. In order to test the reasonability of the results, the correlation between variables and use values were analyzed, and the significance of variables were tested using contingency table and Chi square test method. The results are presented in Table 4.

As can be seen from Table 4, educational level, income level, travel costs and visit frequency have significant effects on WTP, while gender, age and occupation have insignificant effects on WTP. According to the statistics of WTP, educational level has the greatest effects on the mean WTP. The statistical results show that for the WTP with university education or above are 9.68

Table 1. Frequency of use values.

\begin{tabular}{cccccc}
\hline WTP(RMB) & Frequency & Percentage & Effective Percentage & Cumulative Percentage & $S(z)$ \\
\hline 0 & 3 & 1.6 & 1.6 & 1.6 & 98.4 \\
$1-50$ & 30 & 16.2 & 16.2 & 17.8 & 82.2 \\
$51-100$ & 37 & 20.0 & 20.0 & 37.8 & 62.2 \\
$101-150$ & 28 & 15.1 & 15.1 & 53.0 & 47.0 \\
$151-200$ & 33 & 17.8 & 17.8 & 70.8 & 29.2 \\
$201-300$ & 20 & 10.8 & 10.8 & 81.6 & 18.4 \\
$301-400$ & 18 & 9.7 & 9.7 & 91.4 & 8.6 \\
400 above & 16 & 8.6 & 8.6 & 100.0 & 0.0 \\
Total & 185 & 100.0 & 100.0 & & \\
\hline
\end{tabular}


Table 2. Survival function of use values.

\begin{tabular}{cc}
\hline WTP(RMB $)$ & $S(\mathrm{z})$ \\
\hline 0 & 0.984 \\
50 & 0.822 \\
100 & 0.622 \\
150 & 0.470 \\
200 & 0.292 \\
300 & 0.184 \\
400 & 0.086 \\
\hline
\end{tabular}
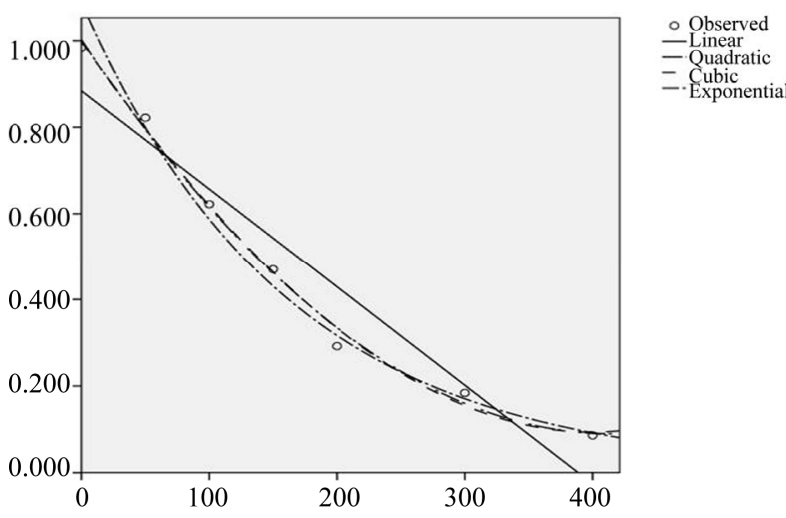

Figure 1. Probability of survival functional values greater than $z$.

Table 3. Regression results of the four functional forms.

\begin{tabular}{cccccccc}
\hline \multirow{2}{*}{$\begin{array}{c}\text { Functional } \\
\text { Form }\end{array}$} & & & & \multicolumn{4}{c}{ Coefficient } \\
\cline { 5 - 8 } & $R^{2}$ & $F$-value & Significance & Constant & $b_{1}$ & $b_{2}$ & $b_{3}$ \\
\hline Linear & 0.924 & 60.776 & 0.001 & 0.884 & -0.002 & \\
Quadratic & 0.994 & 321.047 & 0.000 & 1.004 & -0.004 & $5.254 \mathrm{E}-6$ & \\
Cubic & 0.994 & 161.812 & 0.001 & 1.002 & -0.004 & $3.980 \mathrm{E}-6$ & $2.157 \mathrm{E}-9$ \\
Exponential & 0.982 & 605.135 & 0.000 & 1.085 & -0.006 & & \\
\hline
\end{tabular}

Table 4. Correlation between variables and use values.

\begin{tabular}{ccccc}
\hline Variable & $\chi^{2}$ & Degree of Free & Significance & Correlation \\
\hline Gender & 6.354 & 7 & 0.499 & No \\
Age & 46.544 & 35 & 0.092 & No \\
Occupation & 63.124 & 28 & 0.235 & No \\
Educational Level & 74.618 & 28 & 0.000 & Yes \\
Income Level & 1.604 & 28 & 0.000 & Yes \\
Travel Costs & 68.484 & 28 & 0.001 & Yes \\
Visit Frequency & 16.433 & 7 & 0.028 & Yes \\
\hline
\end{tabular}

times the one with lowest education, which indicate that WTP increase with educational level. According to the mean WTP of the five groups of income level, WTP also increase with income level. The WTP of tourists with RMB 4000 above per month are 12.54 times those with RMB 1000 or below, and the WTP of tourists with RMB 3001 - 4000 are 9.67 times those with RMB 1000 or below. With the travel costs increasing, WTP show a monotonically increasing trend. The WTP of travel costs RMB 1501 - 2000 are 7.46 times those of travel costs RMB 500 below, 5.12 times those of travel costs RMB 501 - 1000. WTP have positively correlated with visit frequency, and the WTP of frequent tourists are greater than those of first tourists.

\subsubsection{Heritage/Selection Values}

The regression results show that the $P$-value of unitary and quadratic coefficient of quadratic form are 0.001 and 0.015 respectively, which indicate that the quadratic form is suitable for the study. But the $P$-value of quadratic and cubic coefficients of cubic form are 0.735 and 0.826 respectively, which indicate that the curve form is not suitable for the study. According to the F-value, the exponential form is also suitable, and its fit is better than the one of quadratic form, therefore a model is constructed as follows:

$$
S(z)=1.0489 \exp (-0.0059 z)
$$

when $S(z)$ equates 0.5 , the median WTP equates 125.57. Then the mean WTP is

$$
\mathrm{WTP}=\int_{0}^{\infty} S(z) \mathrm{d} z=177.78
$$

So the heritage/selection values of Zhangjiajie forest 
Table 5. Survival function of heritage/selection values.

\begin{tabular}{cc}
\hline WTP (RMB) & $S(z)$ \\
\hline 0 & 0.936 \\
50 & 0.843 \\
100 & 0.568 \\
150 & 0.425 \\
200 & 0.281 \\
300 & 0.189 \\
400 & 0.081 \\
\hline
\end{tabular}

recreation are RMB 23.20 - 32.85 billion. The results of correlation between variables and heritage/selection values are shown in Table 7.

As can be seen from Table 7, educational level, income level and travel costs have significant effects on WTP, while gender, age, occupation and visit frequency have insignificant effects on WTP. WTP increase with educational level and the difference between the maximum and minimum pay is RMB 400 . The differences between the WTP of different income level groups are also great.

\subsubsection{Calculate the Preserve Values}

As can be seen from Table 9, the $F$-value and $t$-value of the coefficients of the three function form are statistically significant. According to the fit effect, when $0 \leq z \leq 400$, the quadratic form is the best, and when $z>400$, the exponential form is the best. Therefore, a sub-function is constructed as follows:

$$
S(z)=\left\{\begin{array}{l}
0.9987-0.0040 z+0.0000052 z^{2}(0 \leq z \leq 400) \\
1.0943 \exp (-0.0062 z)(z>400)
\end{array}\right.
$$

when $S(z)$ equates 0.5 , the median WTP equates 156.53. Then the mean WTP is

$$
\begin{aligned}
\mathrm{WTP} & =\int_{0}^{400} S(z) \mathrm{d} z+\int_{400}^{\alpha} S(z) \mathrm{d} z \\
& =190.41+14.78=205.19
\end{aligned}
$$

In 2009, the preserve values of Zhangjiajie forest recreation are RMB 28.92 - 37.91 billion. Therefore, in 2009 the total values of Zhangjiajie forest recreation are the sum of use, heritage/selection and preserve values, which equate RMB 84.50 - 111.89 billion. As shown in Table 10, the use values account for little proportion of the total values, but non-use values account for the majority.

As can be seen from Table 11, educational level and income level have significant effects on WTP, while gender, age, occupation, travel costs and visit frequency have insignificant effects on WTP. To summarize the correlation between variables and the use, heritage/selection, preserve values of forest recreation show that educational level and income level have greater effects on WTP, while gender, age and occupation have relatively less effects on WTP.

\section{Conclusions}

1) According to the number of tourists in 2009 , the use, heritage/selection and preserve values of Zhangjiajie forest recreation were calculated. As can be see from Table 10, use values only account for 35 percent of the total values, while non-use values account for the majority of the total values.

2) The results based on contingency table analysis and Chi square test method show that educational level and

\begin{tabular}{|c|c|c|c|c|c|c|c|}
\hline \multirow{2}{*}{$\begin{array}{l}\text { Functional } \\
\text { Form }\end{array}$} & \multirow[b]{2}{*}{$R^{2}$} & \multirow[b]{2}{*}{$F$-value } & \multirow[b]{2}{*}{ Significance } & \multicolumn{4}{|c|}{ Coefficient } \\
\hline & & & & Constant & $b_{1}$ & $b_{2}$ & $b_{3}$ \\
\hline Quadratic & 0.983 & 114.803 & 0.000 & 0.968 & -0.004 & $5.151 \mathrm{E}-6$ & \\
\hline Cubic & 0.982 & 58.519 & 0.004 & 0.962 & -0.004 & $3.150 \mathrm{E}-6$ & $3.389 \mathrm{E}-9$ \\
\hline Exponential & 0.988 & 370.738 & 0.000 & 1.049 & -0.006 & & \\
\hline
\end{tabular}
income level have significant effects on WTP, while

Table 6. Regression results of heritage/selection values.

Table 7. Correlation between variables and heritage/selection values.

\begin{tabular}{ccccc}
\hline Variable & $\chi^{2}$ & Degree of Free & Significance & Correlation \\
\hline Gender & 7.836 & 7 & 0.347 & No \\
Age & 34.676 & 35 & 0.484 & No \\
Occupation & 57.8 & 28 & 0.172 & No \\
Educational Level & 71.418 & 28 & 0.000 & Yes \\
Income Level & 143.249 & 28 & 0.000 & Yes \\
Travel Costs & 61.422 & 28 & 0.002 & Yes \\
Visit Frequency & 14.968 & 7 & 0.036 & No \\
\hline
\end{tabular}


Table 8. Survival function of preserve values.

\begin{tabular}{cc}
\hline WTP (RMB) & $S(z)$ \\
\hline 0 & 0.968 \\
50 & 0.843 \\
100 & 0.616 \\
150 & 0.470 \\
200 & 0.281 \\
300 & 0.189 \\
400 & 0.081 \\
\hline
\end{tabular}

Table 9. Regression results of preserve values.

\begin{tabular}{|c|c|c|c|c|c|c|c|}
\hline $\begin{array}{l}\text { Functional } \\
\text { Form }\end{array}$ & $R^{2}$ & $F$-value & Significance & \multicolumn{4}{|c|}{ Coefficient } \\
\hline Quadratic & 0.989 & 182.369 & 0.000 & 0.999 & -0.004 & $5.204 \mathrm{E}-6$ & \\
\hline Cubic & 0.989 & 93.763 & 0.002 & 0.993 & -0.004 & $3.226 \mathrm{E}-6$ & $3.35 \mathrm{E}-9$ \\
\hline Exponential & 0.986 & 358.025 & 0.000 & 1.094 & -0.006 & & \\
\hline
\end{tabular}

Table 10. Estimating results of Zhangjiajie forest recreational values(RMB billion).

\begin{tabular}{cccc}
\hline Use Values & Heritage/Selection Values & Preserve Values & Total Values \\
\hline $29.41-38.90$ & $23.20-32.85$ & $28.92-37.91$ & $81.53-109.66$ \\
\hline
\end{tabular}

Table 11. Correlation between variables and preserve values.

\begin{tabular}{ccccc}
\hline Variable & $\chi^{2}$ & Degree of Free & Significance & Correlation \\
\hline Gender & 10.647 & 7 & 0.155 & 0.959 \\
Nge & 21.872 & 35 & 0.420 & No \\
Occupation & 28.851 & 28 & 0.000 & No \\
Educational Level & 65.788 & 28 & 0.000 & Yes \\
Income Level & 124.162 & 28 & 0.086 & No \\
Travel Costs & 61.304 & 28 & 0.174 & No \\
Visit Frequency & 10.262 & 7 & & \\
\hline
\end{tabular}

gender, age, occupation, and visit frequency have insignificant effects on WTP. Educational level has significant effect on WTP, and the WTP of tourists with university education or above is stronger than those of less educated tourists. Income level also has significant effect on WTP, which present that the mean WTP monotonically increase with income level.

3) It can be seen from the results of CVM that educational level and income level have close relationship with WTP, which mean that the tourists with higher education have stronger awareness of ecological environment protect and higher ecological quality requirements, and income level directly restricts WTP. The results suggest that developing economy to improve people's income level and attaching importance to the development of higher education to raise people's awareness of ecological environment protect can enhance WTP. This paper has presented the factors influencing WTP, which have guiding function on planning scientific tourism development program of Zhangjiajie, coordinating the relationship between resources, environment, and economic and social benefits in the process of tourism development, and optimizing tourism system operation.

\section{REFERENCES}

[1] F. Anthony and J. Krutilla, "Determination of Optimal Capacity of Resource Based Recreation Facilities," $\mathrm{Na}$ tural Resources Journal, Vol. 12, No. 3, 1972, pp. 417-444.

[2] A. Randall, B. Ives and C. Eastman, "Bidding Games for Valuation of Aesthetic Environmental Improvements," Journal of Environmental Economics and Management, Vol. 1, 1974, pp. 132-149. doi:10.1016/0095-0696(74)90010-2

[3] K. Arrow, R. Solow, P. R. Portney, et al., "Report of 
NOAA Panel on Contingent Valuations," US Federal Register, Vol. 10, 1993, pp. 4601-4614.

[4] C. B. Richard, A. C. Patricia and J. M. Daniel, "Contingent Valuation," In: D. W. Bromley, Ed., The Handbook of Environmental Economics, Blackwell Publishers Ltd., Hoboken, 1995, pp. 629-654.

[5] T. Swanson and B. Day, "Valuing Water Quality in China: Purpose, Approach and Policy," Journal of Environmental Sciences, Vol. 11, No. 3, 1999, pp. 309-316.

[6] F. Carlsson and S. O. Johansson, "Willingness to Pay for Improved Air Quality in Sweden," Applied Economics, Vol. 32, No. 1, 2000, pp. 661-669.

doi: $10.1080 / 000368400322273$

[7] P. Iamtpakul, K. Hokao and K. Teknomo, "Public Park Valuation Using Travel Cost Method," Proceedings of the Eastern Asia Society for Transportation Studies, Vol. 102, No. 83, 2005, pp. 1249-1264.

[8] M. Rodolfo, R. M. Nayga Jr., R. Woodward and W. Aiew, "Experiments on the Divergence between Willingness to Pay and Willingness to Accept," Economics Bulletin, Vol. 17, No. 4, 2005, pp. 1-5.

[9] A. B. Morancho, A. Ma Fuertes-Eugenio and S. del Saz-Salazar, "A Comparison of Empirical Models Used to Infer the Willingness to Pay in Contingent Valuation," Empirical Economics, Vol. 30, 2005, pp. 235-244. doi:10.1007/s00181-005-0236-X

[10] J. B. Loomis, P. Kent, L. Strange et al., "Measuring the Total Economical Value of Restoring Ecosystem Services in an Impaired River Basin: Results from a Contingent Valuation Survey," Ecological Economics, Vol. 33, No. 1, 2000, pp. 103-117. doi:10.1016/S0921-8009(99)00131-7
[11] B. S. Jorgensen, M. A. Wilson and T. A. Hebelein, "Fairness in the Contingent Valuation of Environmental Public Goods: Attitude toward Paying for Environmental Improvements at Two Levels of Scope," Ecological Economics, Vol. 36, No. 1, 2001, pp. 133-148. doi:10.1016/S0921-8009(00)00210-X

[12] D. Y. Xue, "Estimate the Economic Values of Biodiversity-Case Study of Changbai Mountain Nature Reserve,' China Environmental Science Press, Beijing, 1997, p. 11.

[13] S. B. Wang, P. J. Wang, Z. Y. Hu, et al., "Assessing the landscape Services Value with Contingent Valuation Method: A Case Study on Suzhou Brook, Shanghai City," Journal of Fudan University, Vol. 42, No. 3, 2003, pp. 463-475.

[14] Z. M. Xu, Z. Q. Zhang, G. D. Cheng, et al., "Comparison and Application of Different Contingent Valuation Methods in Measuring Total Economic Value of Restoring Ejina Banners Ecosystem Services," Acta Ecologica Sinica, Vol. 23, No. 9, 2003, pp. 1841-1850.

[15] J. Zhao and K. Yang, "Estimating Urban Inland River Ecosystem Services Value in Shanghai by Contingent Valuation Method," Research of Environmental Sciences, Vol. 17, No. 2, 2004, pp. 49-52.

[16] M. J. Zhang, J. F. Fan, C. X. Hu, et al., "Assessment of Total Economic Value of Improving Atmospheric Quality of Lanzhou," Journal of Arid Land Resources \& Environment, Vol. 18, No. 3, 2004, pp. 28-32.

[17] Y. Yu, E. D. Wang, A. L. Liu, et al., "Documentation Study of Economic Valuation on Recreational Tourism Resources," East China Economic Management, Vol. 23, No. 9, 2009, pp. 140-146. 